\title{
Consider Luxembourg
}

\author{
A small country aiming big.
}

Mention Luxembourg, and it is fair to say that materials science isn't what first comes to mind. To most Europeans at least, the Grand Duchy is mostly known for its burgeoning financial services sector, and as the headquarters for a number of European Union institutions. Delve a little bit deeper into its history, however, and one might recall that the original source of its industrial wealth was steel. Most of the ironworks and foundries may have long closed down, but as part of a wider programme to invest in research, the Luxembourgish government is now looking to revive materials science in the country. The scope of this plan is ambitious, and merits a closer look.

Although one of Europe's smallest countries, counting a little over half a million inhabitants, Luxembourg lies at the heart of the continent, both geographically and politically. Bordering France, Germany and Belgium, it was one of the founding members of the European Coal and Steel Community that ultimately evolved into the modern European Union. As a longstanding proponent of European political and economic integration, the country also boasts a distinctly international society, with over $45 \%$ of its inhabitants born abroad. The growth of the financial services industry over the past two decades has propelled its economy to being among the most competitive in the world. Today, Luxembourgish residents enjoy the highest gross domestic product (GDP) per capita in Europe.

\section{The aim is to establish Luxembourg as a materials research centre of international excellence.}

As impressive as this may all sound, with two thirds of its economic output coming from the service sector, there is at present a serious need for Luxembourg to diversify its economy. As Kreisel, Wirtz and Schiltz outline in their Commentary on page 219 of this issue, the Luxembourgish government is serious about addressing this, and in turn laying the foundations for a sustainable knowledge-based society. A world-class research infrastructure is central to this vision, and the government is investing heavily to achieve this. Since 2000, public spending on research and development has increased from less than $0.1 \%$ to $0.6 \%$ of GDP. More importantly, the country is committed to spending further and is aiming to reach around 2.5\% of GDP for total private and public expenditure by 2020 , which would bring it in line with most other advanced economies in the world.

A number of key areas that leverage Luxembourg's existing expertise and requirements have been identified as strategically important, from biomedical and health sciences, through to information security. Given the country's history in metallurgy, as well as the continued presence of companies specializing in high-performance materials such as Goodyear and Delphi, materials science was also a natural choice for further investment. Clearly, an immediate priority is to consolidate existing knowhow in the private sector and encourage local industry to engage in research and innovation in tandem with academia. More broadly, however, the aim is to establish Luxembourg as a materials research centre of international excellence. In this regard, two developments are especially promising. First, the planned merger, in early 2015, of the two principal public science and technology research centres in the country to create the Luxembourg Institute of Science and Technology (LIST); and second the construction of the Belval City of Science, a large-scale development that, perhaps fittingly, will convert 120 hectares of industrial wasteland into an urban hub for high-level research, innovation, education and culture.

Arguably the most significant challenge will be to attract the talent and knowhow necessary to catapult Luxembourgish research to the next level. The country's main funding body for research, the Fonds Nationale de la Recherche (FNR), has set up a number of programmes specifically designed to provide attractive start-up packages for researchers, the most prestigious of which are, in terms of funding at least, comparable to the Starting and Advanced grants provided by the European Research Council. Moreover, the FNR has actively engaged with other funding agencies around the world and

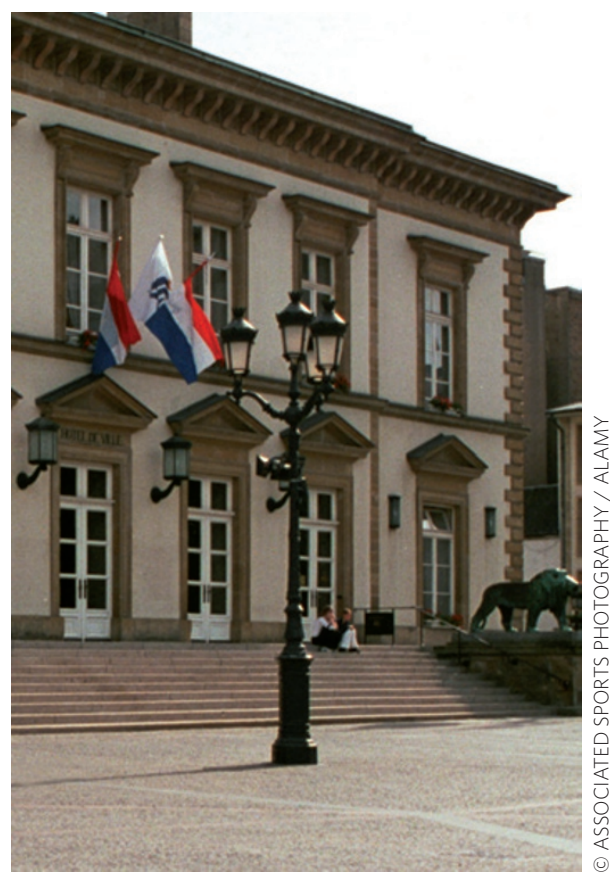

Luxembourg town hall.

signed cooperation agreements that will both raise Luxembourg's profile and provide access to an international network of knowledge that was previously beyond reach. The country's geographical position is also an advantage: Aachen, arguably one of Europe's premier centres for fundamental research, is an hour away by car, and the rest of the continent is also within easy reach. Strengthening ties with such institutions to maximize complementarity would be beneficial for all.

Ultimately, Luxembourg's main advantage may be that it is a rare example of a European country looking to expand its research base. In a continent that has seen a number of players make drastic cuts over the past five years, this in itself makes it stand out. Moreover, the government is keen to follow the example set by other countries that have invested in research, the most obvious comparison being with Singapore. Doubtless there will be challenges ahead as it implements its ambitious strategy, but for now Luxembourg is putting its money where its mouth is.

Corrected after print: 20 February 2014 


\section{Correction}

In the version of the Editorial 'Consider

Luxembourg' originally published (Nature Mater.

$13,215 ; 2014)$, the image of Luxembourg town

hall was wrong. Corrected in the PDF and

HTML versions after print 20 February 2014. 